\title{
Additive manufacturing - a sustainable manufacturing route
}

\author{
Domnița Frățilă ${ }^{1, *}$, and Horațiu Rotaru ${ }^{2}$ \\ ${ }^{1}$ Technical University of Cluj-Napoca, Department of Manufacturing Engineering, Bd. Muncii 103- \\ 105, 400641 Cluj-Napoca, Romania \\ ${ }^{2}$ Iuliu Hatieganu University of Medicine and Pharmacy, Department of Craniomaxillofacial Surgery, \\ Cluj-Napoca, Romania
}

\begin{abstract}
Additive Manufacturing (AM) technologies allow developing and manufacturing very complex shaped parts and functional products with a high level of customization, being a great alternative to Traditional Manufacturing (TM) methods like injection molding, die-casting or machining. Due to the importance of cleaner production in the field of manufacturing processes, sustainability of AM processes needs to be assessed in order to make easier its acceptance and implementation in the industry. Furthermore, the manufacturers can improve their competitiveness and profitability by considering the ecological aspects during the manufacturing step of a product. This paper gives a survey on sustainability issues related to AM.
\end{abstract}

\section{Introduction}

The relevance of the sustainable development and particularly the environment-friendly technologies is already well-known. Nowadays the manufacturing companies are forced to manufacture and deliver cheap and quality products while increasing environmental performance.

According to these, it is strongly necessary to correlate research subjects from Romania with topical international tendencies. Basically, it is needed to set the aspects to be considered for implementation in the practice of new techniques and methods. In the machine building area these deal with influence factors on efficiency of sustainable technologies and their efficient implementation.

A comprehensive analysis of sustainability must consider every step of the product life cycle, from raw materials to disposal at the end of product life, including manufacturing stage, when quantities of materials and energy are consumed [1-3]. Thus, green manufacturing is one step towards sustainable development (Figure 1) [4].

Several investigations have been carried out in the area of machining processes considering environmental impacts. Some studies have been conducted in order to evaluate the manufacturing processes taking into account energy consumption, lubricants use, or lubricants removal. Other works have been made for reducing the lubricants consumption

* Corresponding author: domnita.fratila@,tcm.utcluj.ro 
by minimal quantity lubrication method, high pressure jet-assisted machining or cryogenic machining. Some other studies developed methodologies for ecological impact assessment of TM processes [5-8].

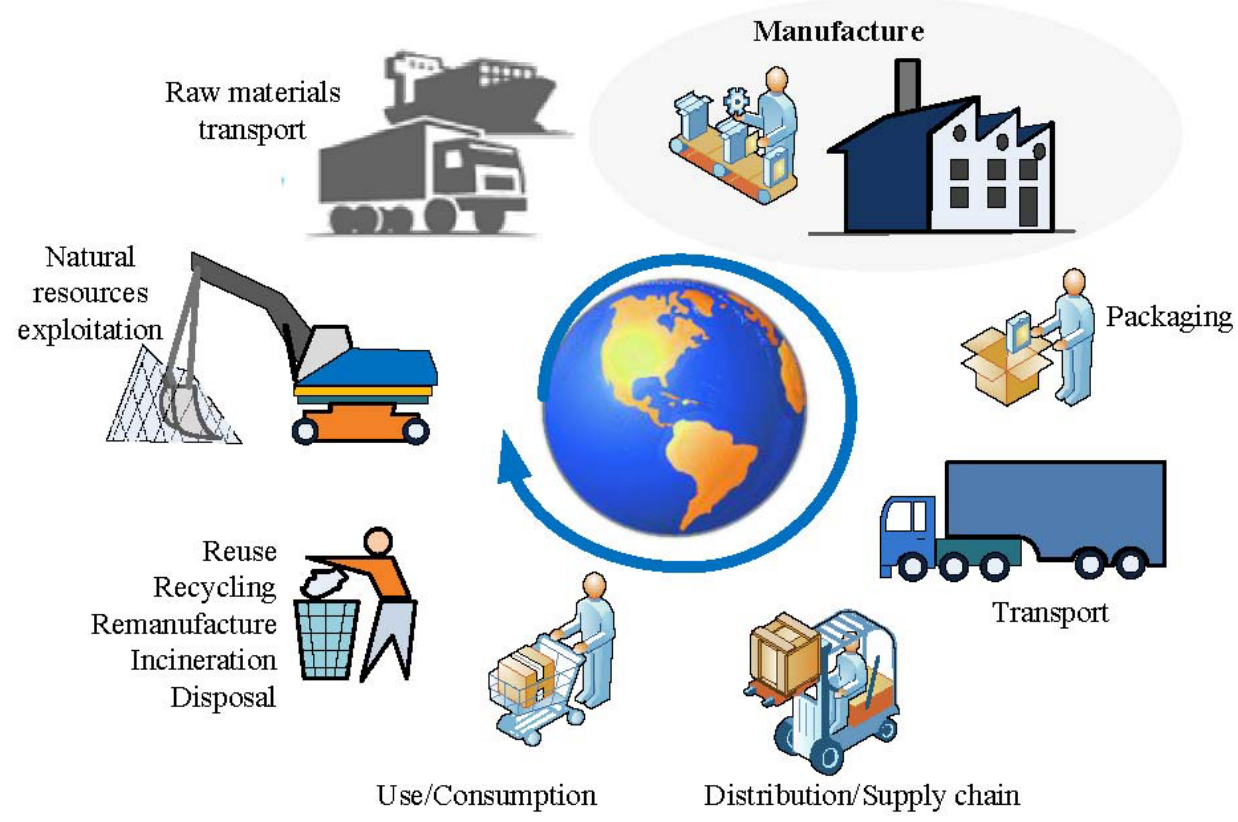

Fig. 1. Stages of product's life cycle [4].

Additive Manufacturing (AM) is a relative young technology that has the potential to fabricate geometrically complex customized products (functional parts and tooling) using less material and producing less waste. AM has the ability to build parts directly from digital models and represents an alternative to TM (e.g. machining, die-casting or injection molding) [2, 5, 9]. AM technologies are particularly suitable in the fields of medicine, automotive industry and aerospace industry where customization, parts' light weighting, and short supply chains are economically valuable [10].

Studies have shown that AM can be a viable option for the industry, but is not widely accepted yet, because of the lack of standards in AM domain. Thus, the use of AM for parts' production is impeded since in the industry the quality assurance depends on standards in selection of manufacturing processes and materials [11, 12].

Related to AM sustainability, only few researches have been conducted. Most of them are focused on electrical consumption of machines and equipment. The studies emphasize the correlation between sustainability and design quality, because the energy consumption depends on part geometry and orientation. Main AM design aspects to consider include: shape and mechanical properties of the part, surface finish, and costs [13-18].

Current practices based on human experience must be transformed into science-based practices through sustainability evaluation. A sustainable manufacturing assessment method to quantify a broad set of metrics needs to be developed using tools such as Design for Manufacturing and Assembly (DFMA) and Life Cycle Assessment (LCA).

LCA for parametric processes model has to be developed allowing estimating the environmental impact of manufacturing stage of parts/products made by AM technologies 
too. Such tool could improve the design of parts, processes and AM equipment with regard to reduce the environmental impacts generated through material flows, waste and energy consumption.

\section{Ecological issues of AM}

Sustainability characterization of AM as a part of industrial production chain is often difficult to do. The quantifiable dimension of such study should include ecological issues of AM related to materials and energy consumption, health and safety, transport and waste management and emphasizes the correlation between sustainability and design quality. The main AM design aspects to consider include: part strength, part flexibility, surface finish, enclosed voids, material cost, machine cost, and process productivity.

AM processes must demonstrate their environmental-friendly potential, by considering the sustainability principles: efficient use of material and energy, industrial waste management, low manufacturing costs, avoidance toxic emissions and materials, health and safety issues, low environmental impacts, improvement of personnel health, safety, economical efficiency, reparability, reusability, recyclability, and disposability of the products made by AM.

\subsection{Energy}

Despite its potential to promote cleaner manufacturing, AM cannot be regarded as an ecological-friendly manufacturing method yet, due to the high energy consumption by using heat processes or lasers to melt plastic and metal or to cure resins. AM equipment is generally not designed to be efficient. Energy loss is considerable and the heat management is poor. At mass-manufacturing scale, AM processes have higher impacts per part than TM. But this is not relevant, because they are replacing small batches of customized parts [19].

If the parts are manufactured by traditional manufacturing processes or $3 \mathrm{D}$ printing, the most important factor for environmental impact is the way how these methods are used. Any of these methods manufacturing only a part per week, but left on the rest of the time, could have higher impact than the same machine at maximal utilization [3, 5].

For TM, material use and waste is the largest impact. For AM electricity use dominates environmental impacts, because the energy usage per item is still very high in the manufacturing stage. The best way to reduce impacts of AM energy use is to reduce the run-time by considering some simple strategies for that: orient parts for the fastest printing, print tubular parts rather than solid; and (if possible) fill the printer bed with multiple parts $[3,5,19]$.

\subsection{Materials}

Reducing the amount of material printed is beneficial for AM sustainability. AM uses several raw materials to create prototypes, parts or functional products based on $3 \mathrm{D}$ digital models by printing layers of materials, but a substantial amount of unused raw materials left behind of $3 \mathrm{D}$ printers.

The variety of materials used in AM includes: metals, polymers, ceramic or composite materials in forms of powders, wires and liquids. AM works with several sorts of materials including powdered or molten polymers (plastics) which are not ideal for environment (even they can be recycled) regardless of what kind of manufacturing techniques is involved. Rarely plastic by-products can be reused, but often the material properties are corrupted, making these materials no longer suitable for parts manufacturing. Some plastics 
are less pollutant than others. Therefore, standardized scales of flammability, toxicity, and reactivity must be consulted for choosing appropriate materials [3, 19].

The use of biodegradable printing materials or newly sand could be a solution. Using polylactic acid or polylactide (PLA, Poly) has more benefits than ABS. PLA is a biodegradable thermoplastic aliphatic polyester derived from renewable resources (corn starch, tapioca roots or sugarcane), being a bio-based polymer (less toxic) and needing lower temperatures in printing, hence affecting energy consumption. Due to all these properties, PLA is a promising bio-plastic, becoming a standard 3D printing material.

Even the toxicity may not be obvious, the health and safety issues in AM should additionally be considered. Toxic gaseous by-products are given off when plastic is heated to high temperatures and melted. The air quality inside the AM job shops needs to be analyzed in order to evaluate the impact of gaseous emissions and ultra-fine particles (UFP) emissions in industrial-scale environment. 3D printers emit low level of UFP, which could cause negative effects on human health including: lung function changes, airway inflammation, enhanced allergic problems, accelerated atherosclerosis, altered heart rate [19].

Materials for Fused Deposition Modeling (FDM) systems seem to be non-toxic developed from a wide range of commercially available thermoplastics. The melting temperatures of these materials should not be exceeded for avoiding the fumes produced during processing. The health problems caused by fumes or by post-processing operations can be: skin, eyes, and respiratory tract irritations.

\subsection{Life cycle}

The environmental impact of products fabrication involves several stages through product life cycle, starting with natural resources exploitation to product disposal, beyond manufacturing process $[5,19]$.

The transport and end of life of the machines (both 3D printers and machine tools) represent a small portion of impacts, amortized by intense utilization, but, if only few parts are made every week, those embodied impacts can be significant.

AM can change the product life cycle by shortening the supply chains and by reducing the fuel amount consumed to ship products. Traditional production target the areas of low labour costs, often far away from the markets where the products are consumed. With AM, the production can be close to the product consumer. This shortening of the supply chain reduces the transport costs associated with it and with the pollution and roads congestion [9].

\subsection{Waste management}

The environment state and the growing of the global consumer economy should be well balanced. Nowadays AM technologies become more widely used in many industrial sectors. Their environmental impact will depend on how these manufacturing methods are used [19].

Compared to conventional manufacturing approaches, AM may have environmental benefits because it does not require tooling. Thus, innovative designs can be created without tooling putting limits on the shapes.

Unfortunately, the opportunity to print quickly a series of variations of a product design can encourage a new kind of pollution by rapid waste generation. A critical AM issue is reuse and remanufacturing of the parts/products.

There is almost no information about waste flows associated with polymeric and metallic AM processes. Some of these flows add actually no value to the part such as: SLS 
powder refresh, FDM support structure materials, post-process heat treatment for reducing residual stresses or energy loss from inefficient laser and optical systems.

FDM machine can have negligible waste but only if the model does not need any support material while printing. The inkjet 3D printer wastes $40 \%$ of its ink without counting supports material $[5,19]$. Depending on geometry and orientation, the support could be more mass than the final part, and this waste is difficult to be recycled.

Summarizing, 3D printers are not really less wasteful. Their waste is not necessarily recyclable and not important compared to their electricity use.

\section{Potential sustainability of AM}

When compared with TM methods, there are some potential sustainability benefits to AM implementation for part production in the industry $[1,3]$ :

- AM improves the efficiency of raw materials use (in powder, liquid or wire form) through its feature referred as net shape manufacturing;

- In addition to cost-efficiency and high freedom in design, AM could become an energy efficient and environmentally friendly manufacturing route due to high rate of material utilization;

- AM can be beneficial from an ecological perspective leading to elimination of fixed tooling, reduced material requirements and reduction of raw materials diversity needed, reduced waste from manufacturing processes;

- AM helps developing parts or products for optimal performance including reduced weight, good mechanical properties and optimal designed parts by incorporating gas flow paths, heating or cooling channels;

- Products made by AM can be 50\% lighter than the same products made through TM. Performance of the final products will be also improved by increasing of energy and fuel efficiency during their life cycle (e.g. by less fuel consumption in aerospace industry) and less pollutant emissions in distribution stage;

- AM allows the fabrication of customized parts in small batches at the right moment and in the place of need (next to the customer), reducing the transportation costs within the supply chains and transportation pollution. Therefore, AM influences for logistics industry are important, with losses for transport sector but positive consequences for environment;

- Shorter product development cycles meaning: less employee-day per part, which indirectly means lower energy consumption.

\section{Proposed research methodology}

The main study goal consists of the predictive tool development that will allow the sustainability evaluation and comparison of the manufacturing processes. The special emphasis should be on evaluation and modeling of the potential environmental impacts in AM. Until now researches have been conducted mainly on electricity consumption of machine tools, considering "in process consumption" and "standby consumption". But a realistic study must take into account all consumed flows of materials, energy, fluids for an accurate impact assessment.

The study proposes the development of a predictive assessment method to evaluate the environmental impacts considering the materials, fluids and energy consumption during the manufacturing step of a part, unused material and parts recycling. The decision-makers need a simplification into single LCA scores by balancing energy and material use, emissions, toxicity, air pollution, water pollution, waste, etc. The single-score methodology normalizes and weights the different impacts $\left(\mathrm{kg}\right.$ of $\mathrm{CO}_{2}$ and $\mathrm{NO}_{\mathrm{x}}$, ppm of particulate 
matter, etc.) into generic units called "points". More points mean more environmental impacts.

The correlation between technological aspects of manufacturing processes and associated ecological issues has to be solved. The study should be conducted by a comprehensive quantitative comparison of $\mathrm{TM}$ processes and $\mathrm{AM}$ technologies to determine which method is most sustainable.

Six major elements that affect the sustainability of manufacturing processes may be taken into consideration: manufacturing cost, energy consumption, and waste management are easily measured, while the last three: environmental impact, personnel health, and operator safety are not easily to quantify.

Considering the above presented aspects, sustainability assessment method will be developed within many stages and steps, as shown in Figure 2.

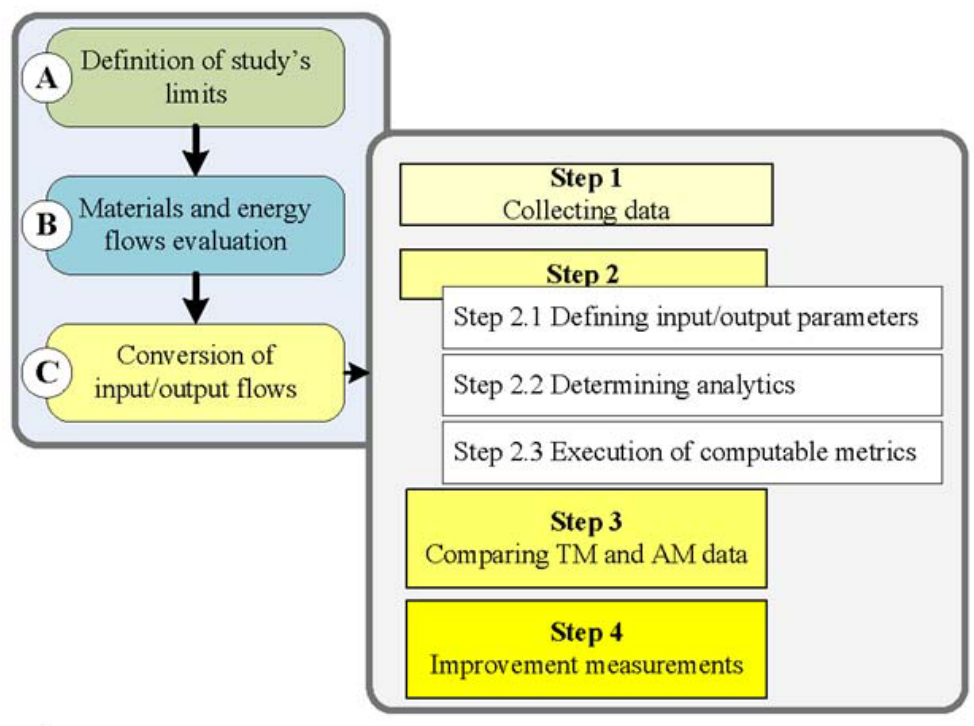

Fig. 2. Study stages.

A. Definition of study's limits. The limits of the analysis have to be clearly defined. Some elements could be neglected, otherwise all the products used in part fabrication should be considered.

B. Evaluation of consumption for all flows. All aspects of manufacturing process from raw material to final part must be examined.

C. Conversion of input/output flows into environmental impact.

The model may provide a framework for assessing and comparing sustainability for different manufacturing process including AM within 4 main steps.

Step 1 involves understanding the process mechanism and collecting relevant data.

Step 2 consists of: 2.1 Defining input (use of material, energy and other resources) and output indicators (product/part, solid waste, liquid waste, emissions) of performance and their computable metrics, 2.2 Determining analytics used for sustainability calculation, 2.3 Applying specific data of manufacturing process and enabling execution of computable metrics. Life cycle inventory data specific to the process will be considered.

Step 3 Comparing AM data generated against other manufacturing processes from industry (e.g. machining, injection molding, etc).

Step 4 Improvement measurements, based on results from previous step. 
A framework for developing sustainable manufacturing metrics and potential interactions among metrics should be established. Metrics cover environmental, economic and social aspects and measure the inputs and outputs of a manufacturing process at a workstation. Workstation level measurements focus on a single machine performing one or more operations, or a piece of auxiliary equipment providing a specific function or doing a specific job with certain tools and materials under particular operations.

Preliminary LCA of AM including energy use, materials consumption in the final parts, material wasted, emissions, transportation and end-of-life disposal of the machines and parts will be performed and compared with conventional/TM processes.

\section{Case study}

The purpose of the case study is to analyze the environmental impacts of two additive manufacturing machines (SLS Sinter Station 2000 and FDM 1650) and a traditional computer numerical control milling machine (HAAS-VF2) from Manufacturing Engineering Department (TU Cluj-Napoca), in order to evaluate their sustainability.

The case study, considering only material and energy consumption, is the first step of methodology development for producing accurate LCA to compare various manufacturing methods. Some elements of the manufacturing systems will be neglected, but a comprehensive evaluation of their environmental performance is done by dividing the each whole process into individual elements such as: material preparation/utilization, energy consumption, material toxicity, and waste disposal. The factors taken into account in terms of environmental performance of manufacturing processes are summarized in Table 1.

Table 1. Analyse factors.

\begin{tabular}{|c|c|c|c|}
\hline Technology & SLS & FDM & Machining \\
\hline Machine & $\begin{array}{c}\text { Sinter Station DTM- } \\
2000\end{array}$ & FDM-1650 & $H A A S-V F 2$ \\
\hline Material & $\begin{array}{l}\text { powder of polyamide, } \\
\text { ABS, titan, elastomers, } \\
\text { polycarbonate }\end{array}$ & $\begin{array}{l}\text { ABS, PLA, PVA, PC, } \\
\text { HDPE, nylon, wax }\end{array}$ & $\begin{array}{l}\text { metals, plastics (ABS), } \\
\text { wood }\end{array}$ \\
\hline Energy & high power laser beam & heat & mechanical energy \\
\hline Operation & $\begin{array}{l}\text { no tool, building step, } \\
\text { infiltration }\end{array}$ & no tool, one step & $\begin{array}{l}\text { cutting tools needed, } \\
\text { multi-steps }\end{array}$ \\
\hline Solid waste & $\begin{array}{l}\text { material chips, unused } \\
\text { material }\end{array}$ & $\begin{array}{l}\text { removed supports, } \\
\text { material chips }\end{array}$ & chips, tool scrap \\
\hline Liquid waste & no & no & lubricants, coolants \\
\hline Emissions & no & fume & $\begin{array}{l}\text { tool particulate, fume, } \\
\text { fluid vapors }\end{array}$ \\
\hline Disposal & $\begin{array}{l}\text { incineration, landfill, } \\
\text { recycling }\end{array}$ & $\begin{array}{l}\text { incineration, landfill, } \\
\text { recycling }\end{array}$ & landfill, recycling \\
\hline
\end{tabular}

$\mathrm{CNC}$ machines energy use is difficult to measure and to attribute to different parts manufactured under different production condition. For CNC machines, about $80-85 \%$ of the energy used by machining equipment is constant, regardless if a part is produced or not and, thus, the energy demand per part is inversely proportional to the material removal rate. CNC machines often utilize auxiliary equipment whose energy use can exceed the cutting energy [20, 21].

The percentage of machine utilization is an important factor in its environmental impact to achieve low impacts, it is not enough that the machine processes a part quickly, but also that it spends as much of its time processing parts. The total processing time consists of basic time (stand-by mode), idle time (partial mode), and machining mode time (full mode). 
Therefore the machine tool used for machining consists of various electricity-consuming elements such as: consumption in the idle state (52\%), cutting energy (7-10\% according to the cutting conditions), spindle rotation (20\%), stage movement (1\%), coolant pump (20\%), numerical control, pressured air, or light [20].

For both AM equipments, Sinter Station 2000 and FDM 1650, the energy consumption is directly dependent on part geometry, finish quality and the manufacturing time that must be minimized for each case. System energy usages in terms of the energy consumption rates (ECR) have been determined. For SLS system the laser, heating, and cooling systems are the greatest contributors to energy used. The process energy is divided into non-processing energy (roller movement - 15\%, piston movement by stepper motors - $25 \%$ and initial heating - 37\%) and laser processing energy (16-20\%). Specific energy consumption is difficult to prescribe because of the variance in build density and height [22]. In the present study case $100 \%$ build density has been considered. For the calculations of energy consumption rates (ECR), only the main processes are considered for the three manufacturing methods. The processing of the material is considered to be done continuously.

Sustainability assessment indicator is calculated by equations (Eq.1- Eq. 6). Electrical energy consumption $(\mathrm{kWh})$, material consumption $(\mathrm{kg})$ and fluid consumption (l) are converted in Pt using characterization factors $\left(f_{\mathrm{ch}}\right)$ [23] according to EcoInvent and EcoIndicator 99 databases [24, 25].

$$
S I=C_{E}+C_{M}+C_{F}+C_{W}
$$

where SI - sustainability indicator

$\mathrm{C}_{\mathrm{E}}$ - contribution of electrical energy consumption

$\mathrm{C}_{\mathrm{M}}$ - contribution of material consumption

$\mathrm{C}_{\mathrm{F}}$ - contribution of fluid use

$\mathrm{C}_{\mathrm{w}}$ - waste contribution

$$
\begin{aligned}
& C_{E}=f_{c h-E} \cdot E C R \\
& E C R=\frac{P}{P P}=\frac{P}{q_{m a t}+\rho_{m a t}}
\end{aligned}
$$

where $f_{\text {ch-E }}$ - electricity characterization factor

$\mathrm{ECR}$ - energy consumption rate $\left(\mathrm{kWh} \cdot \mathrm{kg}^{-1}\right.$ or $\left.\mathrm{kWh} \cdot \mathrm{mm}^{-3}\right)$

$\mathrm{P}$ - electric power consumed during manufacturing $(\mathrm{kW})$

$\mathrm{PP}$ - process productivity $\left[\mathrm{kg}\right.$ material (added or subtracted) $\cdot \mathrm{h}^{-1}$ )

$\mathrm{q}_{\mathrm{mat}}$ - quantity of material (deposed or subtracted) per hour $\left(\mathrm{cm}^{3} \cdot \mathrm{h}^{-1}\right)$

$\rho_{\text {mat }}-$ material density $\left(\mathrm{kg} \cdot \mathrm{cm}^{-3}\right)$

ECR concept is used to facilitate comparison among manufacturing processes, being defined as the energy consumed in the production of material unit. For subtractive processes, ERC is defined as joule (or $\mathrm{kWh}$ ) per unit volume of material $\left(\mathrm{kWh} \cdot \mathrm{cm}^{-3}\right)$. For the case of SLS and FDM, ECR is usually expressed as joule (or kWh) per unit mass of material $\left(\mathrm{kWh} \cdot \mathrm{kg}^{-1}\right)$, because the material density is influenced by the process parameters.

$$
\begin{gathered}
C_{M}=\left[e_{n}+k \cdot\left(1-e_{n}\right)\right] \cdot d_{p} \cdot t_{\text {man }} \cdot f_{c h-M} \\
C_{M}=\left(V_{w p}-V_{p}\right) \cdot f_{c h-M}
\end{gathered}
$$

where $f_{\text {ch-M }}$ - material characterization factor

$\mathrm{e}_{\mathrm{n}}$ - nozzle efficiency

$\mathrm{k}$ - weighting factor to weight the impact of lost powder compared with fused powder

$\mathrm{d}_{\mathrm{p}}$ - powder flow rate $\left(\mathrm{kg}\right.$ material (added or subtracted) $\cdot \mathrm{h}^{-1}$ )

$\mathrm{t}_{\text {man }}-$ manufacturing time $\left(\mathrm{cm}^{3} \cdot \mathrm{h}^{-1}\right)$ 
$\rho_{\text {mat }}-$ material density $\left(\mathrm{kg} \cdot \mathrm{cm}^{-3}\right)$

$\mathrm{V}_{\mathrm{wp}}$ - workpiece material volume

$\mathrm{V}_{\mathrm{p}}$ - part material volume

$$
C_{F}=\left(d_{c}+d_{f}\right) \cdot t_{\text {man }} \cdot f_{c h-G}+d_{c o} \cdot t_{\text {man }} \cdot f_{c h-c o}
$$

where $d_{c}$ - carrying gas flow

$\mathrm{d}_{\mathrm{f}}-$ protecting gas flow

$\mathrm{d}_{\mathrm{co}}-$ coolant flow

$\mathrm{f}_{\text {ch-G }}$ - gas characterization factor

$\mathrm{f}_{\text {ch-CO }}-$ coolant characterization factor

LCA analyze is conducted using EcoIndicator 99 method and SimaPro 7 software. This method considers the following impact inventory categories: carcinogens, respiratory organics, respiratory inorganics, climate changes, radiation, ozone layer, ecotoxicity, acidification/eutrophication, land use, and fossil fuels.

Environmental impacts may cause damage to human health and ecosystems, and deplete natural resources including: climate change, ozone depletion, toxicity, etc. To make appropriate decisions related to manufacturing processes, these aspects are evaluated even if they seem less concrete than data such as "kg of waste" or "kWh of energy use" and being achieved by LCA, using types of impacts normalized and weighted to calculate single score metrics [24].

The scores are expressed in Eco-Indicator points $(\mathrm{Pt})$, which allows comparing the environmental impacts due materials, fluids and electrical energy consumption that have not the same unit. The size of the Pt unit represents one thousandth of the yearly environmental load of an average citizen in Europe [24]. Several variables are first normalized to disability adjusted loss of life years for humans, probable loss of species per year for environmental impacts, and loss of resource availability as measured in financial cost of resources, before the final normalization to points [25].

\section{Results and discussions}

Due to the limitation of materials usable by AM, it is not possible to consider the same materials for the case study, but for making fair comparison, similar materials are considered: ABS P400 for FDM process and machining and polymer PA12 for SLS. Table 2 indicates the ECRs, calculate for every manufacturing method. Processing parameters considered are: $\mathrm{V}$ - scanning (drawing) speed $(\mathrm{mm} / \mathrm{sec}) ; \mathrm{W}$ - road width size $(\mathrm{mm}) ; \mathrm{T}-$ layer thickness $(\mathrm{mm}) ; \rho$ - material density $\left(\mathrm{kg} \cdot \mathrm{mm}^{-3}\right) ; \mathrm{P}$ - power rate $(\mathrm{kW}) ; \mathrm{k}$ - process overhead coefficient $(0.6-0.9), \mathrm{PP}$ - process productivity $=\mathrm{V} \cdot \mathrm{W} \cdot \mathrm{T} \cdot \rho \cdot 3600 \cdot \mathrm{k}\left(\mathrm{kg} \cdot \mathrm{h}^{-1}\right)$. Some information from data bases and literature have been used.

The environmental performances are calculated for $1 \mathrm{~kg}$ material processed, making one part per day and lefting machines idling the rest of the time. The following assumptions have also been considered: ABS milling is done without cooling/lubrication (dry machining), an average consumption of support material up to $25 \%$ from part material for FDM, FDM is printing parts at 100 percent fill, SLS machine prints with 100 per cent model material, postprocessing, disposal of the parts and waste have been neglected. 
Table 2. ECRs of equipments.

\begin{tabular}{|l|l|l|l|}
\hline & Sinterstation 2000 & \multicolumn{1}{|c|}{ FDM 1650 } & HAAS-VF2 \\
\hline Material & $\begin{array}{c}\text { Polymer PA12 } \\
(100 \% \text { solid part })\end{array}$ & $\begin{array}{c}\text { ABS P400 } \\
(100 \% \text { solid part })\end{array}$ & ABS P400 \\
\hline Support material & & $\begin{array}{l}\text { Terpolymer (mix acid, } \\
\text { styrene, buthyl acrylate })\end{array}$ & \\
\hline Material density, $\rho\left(\mathrm{g} \cdot \mathrm{cm}^{-3}\right)$ & polymer powder & 1.04 & 1.04 \\
\hline Scanning speed,V $\left(\mathrm{mm} \cdot \mathrm{sec}^{-1}\right)$ & 3000 & 2 & \\
\hline Road width size, $\mathrm{W}(\mathrm{mm})$ & 0.4 & 1.4 & \\
\hline layer thickness, $\mathrm{T}(\mathrm{mm})$ & 0.15 & 0.4 & \\
\hline Specific gravity & 1.08 & 1.05 & 0.9 \\
\hline $\mathrm{K}$ & 0.6 & 0.9 & 22.4 \\
\hline P $(\mathrm{kW})$ & 16.8 & 1.32 & $\begin{array}{l}\text { influenced by } \\
\text { process } \\
\text { parameters }\end{array}$ \\
\hline PP $\left(\mathrm{kg} \cdot \mathrm{h}^{-1}\right)$ & 0.42 & 0.004 & $\begin{array}{l}13.9 \cdot 10^{-6} \\
\left(\mathrm{kWh} \cdot \mathrm{mm}^{-3}\right)\end{array}$ \\
\hline ECR & & & 0.57 \\
\hline EI for energy $\left(\mathrm{kWh}^{-1}\right)$ & $40\left(\mathrm{kWh} \cdot \mathrm{kg}^{-1}\right)$ & $346.5\left(\mathrm{kWh} \cdot \mathrm{kg}^{-1}\right)$ & 0.57 \\
\hline
\end{tabular}

Environmental performances of processes, under conditions and assumptions mentioned in the previous section and Table 2, are presented in Figures 3-5.

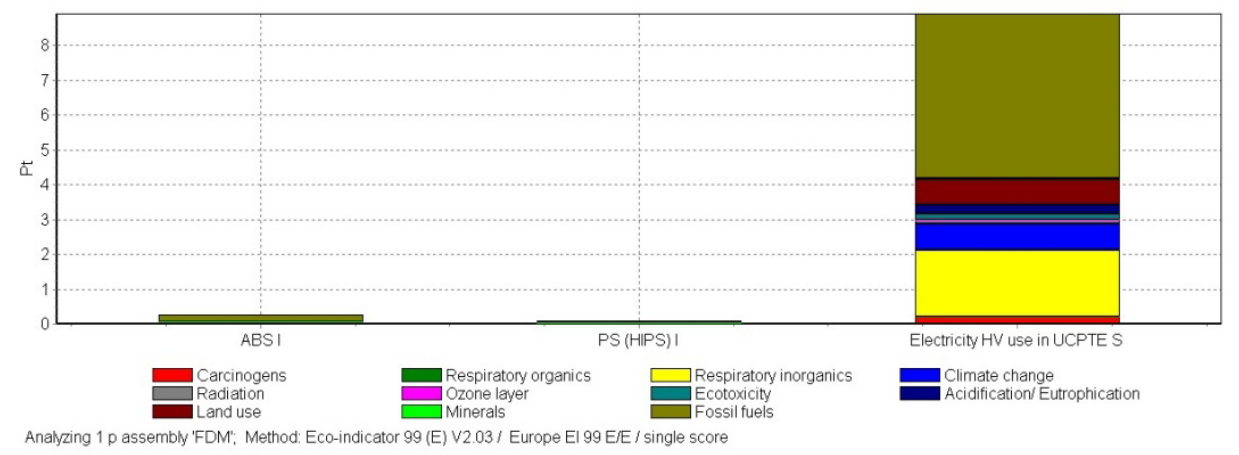

Fig. 3. FDM sustainability indicator.

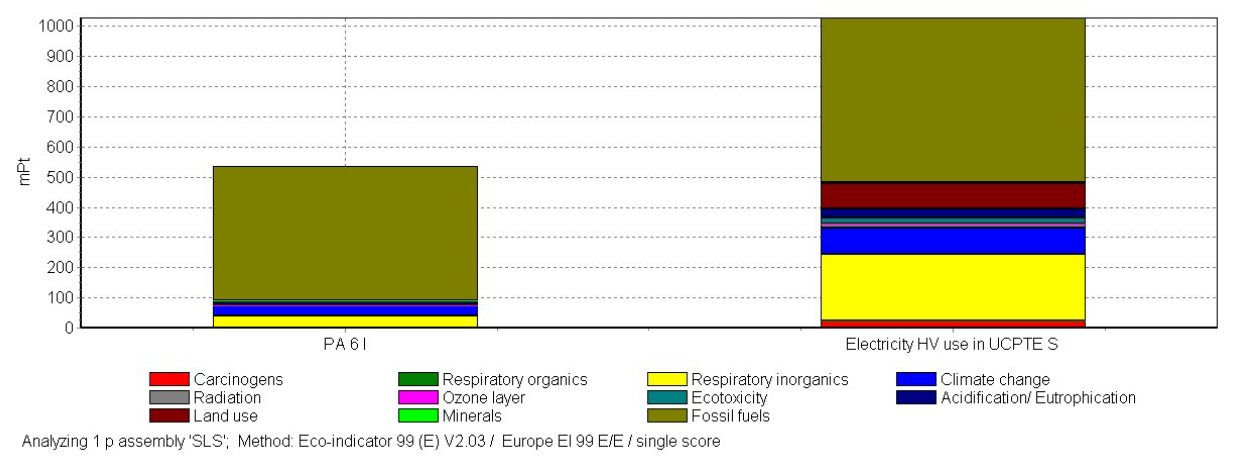

Fig. 4. SLS sustainability indicator. 


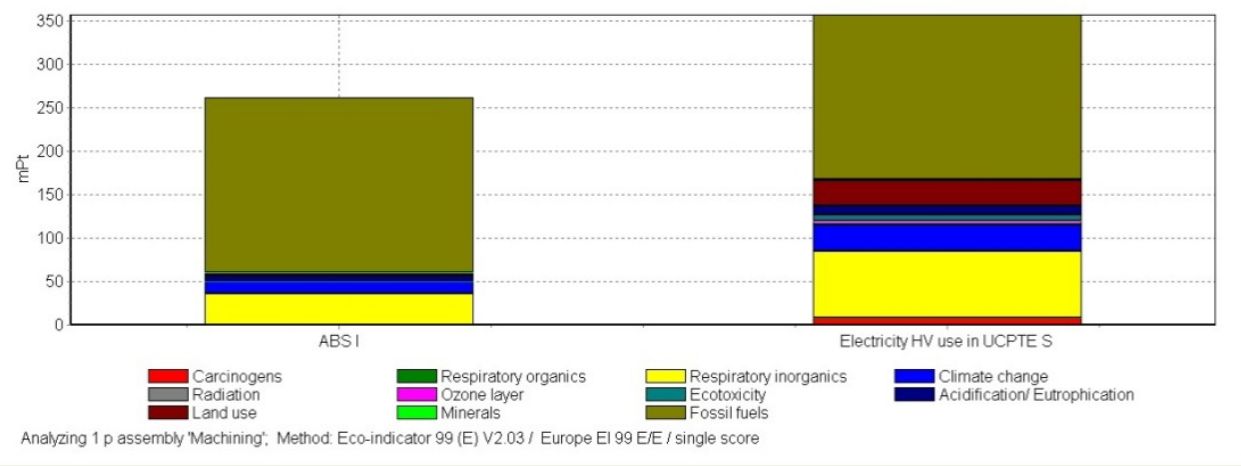

Fig. 5. Milling sustainability indicator.

Diagrams in figures presented above show the individual impacts for FDM, SLS and milling processes. It should be noted that of 11 types of impacts considered by EI 99 method, 4 are dominant for all cases: fossil fuels, respiratory inorganics, land use, and climate changes. At maximum utilization without considering the waste (chips and metalworking fluids), machining scored well for both material usage (260 $\mathrm{mPt})$ and energy consumption $(350 \mathrm{mPt}$ ) compared with SLS $(550 \mathrm{mPt} / 1020 \mathrm{mPt})$ and FDM $0.2 \mathrm{Pt} / 9 \mathrm{Pt})$.

The comparison of sustainability indicators of the manufacturing methods considered is presented in Figure 6. The meaning that AM is generally more sustainable than substractive methods because it does not waste as much materials is not confirmed. The AM energy used can exceed the saving in material impacts. Some 3D printers still have high material impact because of producing about 40 per cent waste and using material with high toxicity.

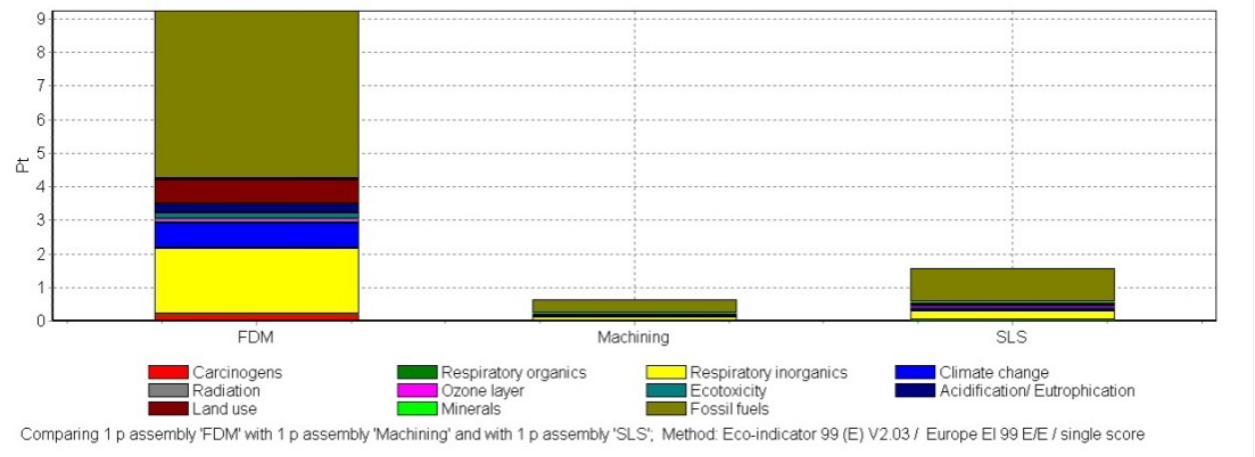

Fig. 6. Comparison of sustainability indicators per inventory subcategories.

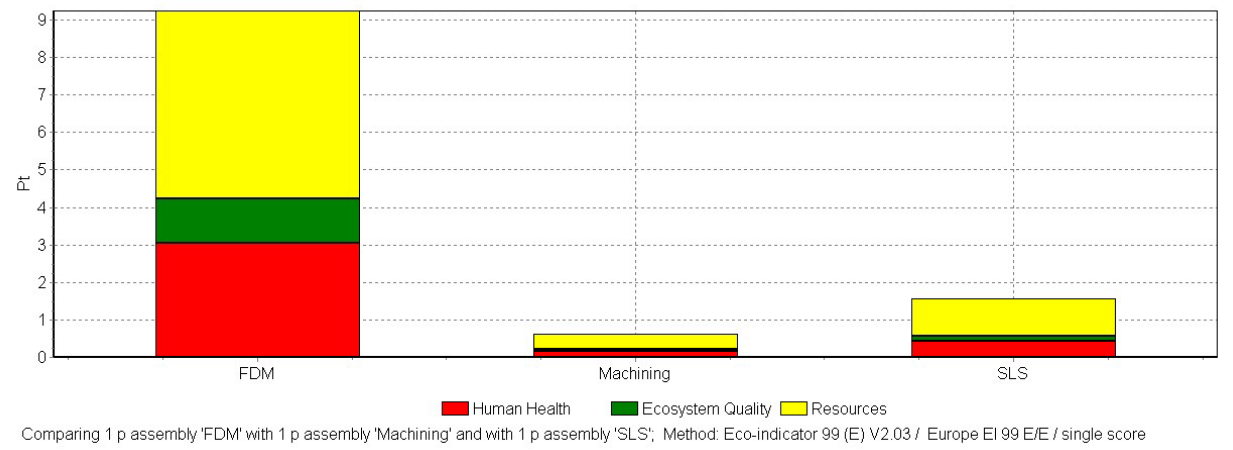

Fig. 7. Comparison of sustainability indicators per inventory main categories. 
This case study indicates the relative sustainability of AM and TM manufacturing methods. As Figure 7 shows, FDM impact seems to be 10 times higher than milling's impact and 5 times than SLS. These results can be validate just across the specific scenario considered, being influenced by local conditions proposed and symplifying assumptions described above.

It can not categorically state that AM is more sustainable than machining or vice-versa. For each process the research has to be continued, because the results could vary in a wide range according to: the manufacturing strategy, usage scenario of the machines, build time related to part volume and part complexity, part orientation, etc.

\section{Conclusions}

The key knowledge gained from this investigation is given below.

AM has the potential to lower costs and to be more energy efficient than conventional processes. One main issue to analyze the energy efficiency of $A M$ is the fact that $3 \mathrm{D}$ machines vary in energy consumption and that energy use is dependent on a several variables, including materials, load and patterns used.

It is strongly necessary an individual comprehensive evaluation of each manufacturing on order to achieve a realistic comparison of the processes.

The sustainability of AM vs TM depends primarily on the utilization rate of the machines. A high utilization reduces the idle energy use and amortizes the impact of each machine.

For both $\mathrm{AM}$ and $\mathrm{CNC}$ machines the electricity use has the dominant impact. Both cause a certain amount of material waste (from original material being removed, from support material, from unused powder at SLS), but for CNC (at maximum utilization) material waste and metalworking fluids become dominant. The electricity use is a largely time-dependent.

Within the next research step the manufacturing processes need to be analyzed considering the part geometry, part orientation, finish quality through their effects on the processing time.

The impacts and perspectives of study can be summarized as following.

Implementation of AM processes can be impeded by inability to compare AM performance against TM methods. Planning decisions for an appropriate selection of manufacturing process and material for specific application require a better knowing and assessment of these elements. Due to growing environmental concerns for manufacturing processes, it needs to analyse the potential environmental impacts of AM by understanding, comparing and characterizing the AM processes for sustainability.

The study result is an efficient tool, contributing to the requests in the field of environmental pollution related to both traditional and additive manufacturing processes, with a significant ecologic and economic impact by decreasing material and energy inputs, improving process results, minimizing waste.

Traditional manufacturers and AM job shops owners may make an informed decision about which technology to use or purchase. Furthermore, the manufacturers of 3D printers can improve their competitiveness and their profitability by considering the ecological aspects during the manufacturing step of a product.

Comprehensive assessment method, based on sustainability metrics, should address the needs of all stakeholders, facilitate growth and innovation.

This paper was supported by the AMaTUC Project, receiving funding from the European Union's Horizon 2020 Research and Innovation Programme under grant agreement No 691787. 


\section{References}

1. K. Kellens, R. Renaldi, W. Dewulf, J. Kruth, J.R. Duflou, Rapid Prototyping J 20, 459-470 (2014)

2. F. Le Bourhis, O. Kerbrat, L. Dembinski, J. Hascoet, P. Mognol, Procedia CIRP 15, 26-31 (2014)

3. F. Le Bourhis, O. Kerbrat, J. Hascoet, P. Mognol, Int J Adv Manuf Tech 69, 19271939 (2013)

4. O. Roş, D. Frățilă, Ecoproiectare / Ecodesign (Casa Cărții de Ştiință, Cluj-Napoca, 2007)

5. J. Faludi, C. Bayley, S. Bhogal, M. Iribarne, Rapid Prototyping J 21, 14-33 (2015)

6. F. Pusavec, J. Kopac, J Ad Prod Eng Manag 3, 151-160 (2009)

7. F. Pusavec, P. Krajnik, J. Kopac, J Clean Prod 18, 174-184 (2010)

8. F. Pusavec, D. Kramar, P. Krajnik, J. Kopac, J Clean Prod 18, 1211-1221 (2010)

9. M. Kreiger, J.M. Pearce, ACS Sust Chem Eng 1, 1511-1519 (2013)

10. P. Berce et al, Aplicațiile medicale ale tehnologiilor de fabricație prin adăugare de material / Medical applications of Additive Manufacturing technologies (Editura Academiei Române, Bucureşti, 2015)

11. M. Baumers, C. Tuck, R. Wildman, I. Ashcroft, E. Rosamond, R. Hague, Transparency Built-In. J Ind Ecol 17, 418-431 (2013)

12. M. A. Krieger, M.L. Mulder, A.G Glover, J.M. Pearce, J Clean Prod 70, 90-96 (2014)

13. D. Baechler, J. DeVuono, J.M. Pearce, Rapid Prototyping J 19, 118-125 (2013)

14. S. S. Muthu, M.M. Savalani, Handbook of sustainability in additive manufacturing, (Publisher Springer Singapore, 2013)

15. P. Ratnadeep, S. Anand, J Manuf Syst 31, 429-437 (2012)

16. R. Sreenivasan, A. Goel, A., D.A. Bourell, Physics Procedia 5, 81-90 (2010)

17. M. D. Tabone, J.J. Cregg, E.J. Beckman, A.E. Landis, Envir Sci Tech 44, 8264-8269 (2010)

18. B. T. Wittbrodt, A.G. Glover, J. Laureto, J., G.C. Anzalone, D. Oppliger, J.L. Irwin, J.M. Pearce, Mechatronics 23, 713-726 (2013)

19. S.S. Muthu, M.M. Savalani, Handbook of sustainability in additive manufacturing (Publisher Springer Singapore, 2016)

20. J.B. Dahmus, T.G. Gutowski, ASME IMECE, 5 (2004)

21. A. A. Munoz, P Sheng, J Mater Process Tehnol 53, 736-758 (1995)

22. R. Sreenivasan, A. Goel, D.L. Bourell, Phys Procedia 5, 81-90 (2010)

23. Y. Luo, Z. Ji, M.C. Leu, R. Caudill, Inst Electr Electron Eng,1-6 (1999)

24. http://www.ecoinvent.org/database/database.html

25. https://www.pre-sustainability.com/download/EI99_Manual.pdf 